\title{
CARTAS A LA DIRECTORA
}

CARTA ABIERTA DE DIMISIÓN DE LOS MIEMBROS DEL CONSEJO DE REDACCIÓN CARLOS FURIÓ MAS Y DANIEL GIL PÉREZ

Querida amiga,

Enseñanza de las Ciencias nació hace ya casil 10 años, fruto de una voluntad colectiva de impulsar y difundir la naciente investigacion sobre Didáctica de las Ciencias en nuestro país. Durante todo este tiempo, la colaboración entre los equipos catalán y valenciano creadores de la revista ha sido, pensamos, muy satisfactoria, sin que la distancia geográfica ni otras razones hayan dificultado una actividad que creemos ha sido fructífera, $y$, para nosotros, gratificante.

Comprenderás, pues, lo difícil que nos ha resultado tomar la decisión que da título a esta carta. Los motivos de nuestra dimisión no están relacionados de ninguna manera con nuestro trabajo en Enseñanza de las Ciencias sino que ha sido el resultado de una de esas tristes historias de trabas y hostigamientos que desgraciadamente abundan en cualquier comunidad y que ha afectado a nuestro trabajo en el Servei de Formació Permanent de la Universitat de València, desde donde realizábamos el trabajo para la revista. Nada de qué sorprenderse ni indignarse excesivamente, si no fuera porque esta vez se ha llegado a extremos -como transformar un concurso público en elec- ción a dedo- que merecían un enérgico ¡bastał

A partir del próximo número nuestros nombres ya no figurarán entre los que componen el Consejo de Redacción de Enseñanza de las Ciencias. Estamos convencidos, sin embargo, de que podremos seguir disfrutando de su aparición, ahora como simples lectores.

Reiteramos nuestra satisfacción por el trabajo común de todos estos años. Con nuestros mejores deseos.

\section{Carlos Furió Mas y Daniel Gil Pérez}

\section{NOBLEZA OBLIGA}

\section{Queridos Carlos y Daniel:}

La publicación de vuestra carta me ha hecho sentirme de algún modo obligada a escribir estas líneas a título personal.

No voy a referirme a las graves acusaciones que hacéis, ni entrar siquiera a valorar los motivos que han originado vuestra decisión porque, como bien decís, son completamente ajenos a Enseñanza de las Ciencias.

Quiero simplemente corresponder al testimonio, que vosotros habéis querido hacer público, cuando valoráis el trabajo en común durante todos estos años. Por eso os doy a los dos las gracias.

También para mí el trabajo en común de estos años ha sido grato y gratificante; $y$ sé muy bien que, aun cuando a ello han contribuido muchas otras personas, vuestra coiaboración ha sido fundamental.

No me importa recordar una vez más que hace ya casi diez años vinisteis los dos a proponerme la realización de un ambicioso proyecto que tomaría luego forma como Enseñanza de las Ciencias.

La concreción y puesta en práctica de la idea no hubiera sido posible si la ilusión y el interés que todos pusimos no hubiese encontrado el apoyo del YCE de la Universitat Autònoma de Barcelona y del entonces ICEde la Universitat de València, que proporcionaron el marco institucional necesario. La conjunción de voluntades y esfuerzos de personas e instituciones permitió nacer entonces a Enseñanza de las Ciencias y continúa posibilitando su consolidación, como instrumento impulsor y difusor de la investigación didáctica de las ciencias.
Pero las instituciones, como las personas, tienen sus grandezas y sus miserias, sus posibilidades y sus limitaciones. Sabéts que siempre he creído necesario conocer bien las segundas para poder desarrollar mejor las primeras. Me consta, además, que ese ha sido el espiritu desde el que nos hemos alineado siempre en el equipo de redacción de Enseñanza de las Ciencias.

Estoy convencida, por otra parte, que vosotros seguís siendo los primeros en compartir el deseo de que la Revista continíe desarrollando su labor cada día más y mejor, y me gustaría que vuestras aportaciones pudieran contribuir a ello.

Este es mi deseo sincero y mi abierta invitación a los dos.

Berta Gutiérrez Reñon 